Research Article

\title{
Ammunition Type Optimization Based on Damage Ability Matching
}

\author{
Yuan Li $\left(D,{ }^{1}\right.$ Xianming Shi $\left(D,{ }^{1}\right.$ Yajuan $\mathrm{Li}^{2}$ Wei Xia, ${ }^{2}$ and Jiangbo Zhao ${ }^{2}$ \\ ${ }^{1}$ Department of Equipment Command and Management, Shijiazhuang Campus, Army Engineering University, \\ Shijiazhuang 050003, China \\ ${ }^{2}$ Department of Mechanized Infantry, Shijiazhuang Campus, Army Infantry College, Shijiazhuang 050227, China
}

Correspondence should be addressed to Xianming Shi; sxm@nudt.edu.cn

Received 21 June 2021; Revised 16 July 2021; Accepted 23 July 2021; Published 29 July 2021

Academic Editor: Zaoli Yang

Copyright ( 92021 Yuan Li et al. This is an open access article distributed under the Creative Commons Attribution License, which permits unrestricted use, distribution, and reproduction in any medium, provided the original work is properly cited.

\begin{abstract}
At present, there exist many kinds of new ammunition, with great differences in application occasions. In the process of ammunition preparation, it is usually necessary to configure a variety of ammunition to meet the needs of attacking different targets. It is essentially a multiple criteria decision-making problem to select the appropriate ammunition type for different targets and provide a reliable decision support for accurate ammunition support. On this basis, the matching degree of ammunition target damage ability is selected as the ammunition type optimization standard, the objective weighting method, entropy weight method, is selected to determine the evaluation index weight, and the VIKOR method is used to gather the ammunition type optimization evaluation value, which overcomes the uncertainty caused by subjective weighting and the information loss caused by index value conversion and takes into account the group benefit value and individual regret value. Through an example, the sensitivity analysis of the decision mechanism coefficient in the VIKOR method is carried out, and the results are compared with those of the TOPSIS method to verify the stability and effectiveness of this method in the process of ammunition type optimization.
\end{abstract}

\section{Introduction}

Ammunition type optimization is the core content of ammunition demand structure [1] optimization and is one of the important decision-making behaviors in the process of accurate ammunition support. The main objective of ammunition type optimization based on damage ability matching is to reasonably allocate ammunition types for different targets on the premise of obtaining relevant evaluation indexes of ammunition target damage ability matching degree [2], so as to ensure the scientificity and accuracy of ammunition type supply in ammunition support process. At present, people pay more attention to the research of the ammunition consumption prediction scheme, but less on the optimization of ammunition types. The former focuses on the total amount of ammunition consumption in a war, while the latter focuses on the category proportion of ammunition demand, that is, the ammunition demand structure. However, since there is no scientific and reasonable method to select the type of ammunition, resulting in that, although the quantity of ammunition is well prepared in actual combat, but for specific targets, there may be a big difference in the strike effect or even "no ammunition available" phenomenon due to improper preparation of the type of ammunition. In this study, guided by the above problems, the multiple criteria decisionmaking method based on relevant factors is used to establish the ammunition type optimization model, and the stability and effectiveness of the model are verified by example analysis.

On the research of weapon equipment decision-making methods, scholars discuss from different angles, mainly focusing on the following two aspects. (1) The method based on the analytical model [3]. The typical model constructed by this method is the weapon target assignment problem $[4,5]$. It mainly discusses how to find the optimal weapon target combination scheme through the construction of the model. According to whether the time factor is considered, the model includes two types. The first type is the static WTA model [6]. The basic model of the static WTA problem is 
described in literature $[7,8]$. The solution methods of the static WTA model mainly include the enumeration method and linear programming method in the traditional algorithm, and intelligent algorithm in heuristic algorithm [9], such as the genetic algorithm used in literature [10, 11], particle swarm optimization algorithm used in literature [12], and simulated annealing algorithm proposed in literature [13]. The second type is the dynamic WTA model [14-16]. The dynamic WTA model mainly considers the impact of current decisions on future operations. For example, the dynamic programming method was used to solve the model in literature [17], the dynamic resource constraint algorithm was used in literature [18], and the constraint based nonlinear programming model was proposed in literature [19]. (2) Methods based on multiple criteria decision-making [20]. Multiple criteria decision-making is divided into multiattribute decision-making (finite) and multiobjective decision-making (infinite) according to whether the number of alternatives is limited or not. The research content mainly includes four aspects. One is the determination of the evaluation index system, such as the equipment effectiveness evaluation system established in literature $[21,22]$. The second is to determine the set of alternatives. The third is the calculation of evaluation index weight, for example, in literature [23], AHP and PCA were used to determine the evaluation index weight of the candidate equipment set. In literature [24], the entropy method was used to determine the evaluation index weight of the guided ammunition configuration scheme. The fourth is scheme ranking and optimization. For example, in literature [25], a language weighted integration operator was used to synthesize evaluation values, and in literature [26], a weapon equipment evaluation model based on the TOPSIS method was established.

After combing, it is found that the optimization of ammunition type is essentially a multiple criteria decisionmaking problem [27]. The essence of multiple criteria decision-making problem [28] is to sort and select a group of alternatives by using the existing decision information in a certain way. At present, there is no research on the application of the multiple criteria decision-making method to ammunition type optimization, but most of the existing literatures use the multiple criteria decision-making method in combat application, and the commonly used method is entropy weight TOPSIS [29], that is, the evaluation method of the integration of the entropy weight method and TOPSIS method. For example, in reference [30-34], the entropy weight TOPSIS method is used to determine the index weight and evaluation value, and the optimization model of target, position, and combat plan in combat application is established. The entropy weight VIKOR method is used in references $[24,35,36]$ to solve the problem of equipment optimization and sequencing in combat application. Both the TOPSIS method and VIKOR method are multiple criteria decision-making methods based on an ideal solution. The basic idea is to determine the positive and negative ideal solutions first and then to determine the priority according to the proximity between the index value and the ideal solution. The TOPSIS method can fully consider the group benefit and find out the scheme closest to the ideal solution, but it does not consider the individual regret [37]. It is easy to produce the situation that the group is satisfied and the individual is not satisfied. The VIKOR rule makes up for the deficiency that the TOPSIS method does not considers the individual regret, considers the compromise relationship between group benefit and individual regret, and obtains a compromise ranking scheme by maximizing group benefit and minimizing individual regret, so as to prevent the negative effects of individual poor indicators from being neutralized by other indicators. Therefore, the entropy weight VIKOR method is used to optimize the types of ammunition in this study.

After reviewing the above documents, it is found that many achievements have been made in the research of decision-making methods of weapons and equipment, but there is not a set of scientific and reasonable decisionmaking methods in the optimization of ammunition types. In view of the shortcomings of the existing research, this study analyzes the properties of ammunition and target, selects the matching degree of damage ability as the evaluation index of decision-making, and proposes a multiple criteria decision-making method based on entropy weight and VIKOR. Meanwhile, the sensitivity of the VIKOR method is analyzed, and the results are compared with the TOPSIS method, which verifies the stability and effectiveness of this method in the process of ammunition type optimization.

\section{Description of Ammunition Type Optimization Problems Based on Damage Ability Matching}

The essence of ammunition type optimization is the best match between ammunition and target. This study starts from the characteristics of ammunition and target, takes the matching degree of ammunition damage ability, and targets antidamage ability as the optimization standard to sort and select ammunition types. It can be abstracted as the following form of the multicriteria decision-making problem: in the ammunition preparation process, the target set is $T=\left\{t_{j} \mid j=1,2, \ldots, m\right\}$, for the alternative ammunition set $A=\left\{a_{i} \mid i=1,2, \ldots, n\right\}$, according to the established evaluation index $C=\left\{c_{l} \mid l=1,2, \ldots, k\right\}$, the decision maker collects and judges the ammunition information, respectively. Let $\omega_{l}$ be the weight of ammunition evaluation index $c_{l}$. The multicriteria decision-making problem can be expressed by matrix as follows:

$$
D=\left[\begin{array}{cccc}
y_{11} & y_{12} & \cdots & y_{1 k} \\
y_{21} & y_{22} & \cdots & y_{2 k} \\
\vdots & \vdots & \vdots & \\
y_{n 1} & y_{n 2} & \cdots & y_{n k}
\end{array}\right],
$$

where $y_{i l}$ is the evaluation value of ammunition $a_{i}$ under the evaluation index $c_{l}$.

From the above analysis, we can see that the key to solve the problem of ammunition type optimization lies in the 
following: (1) determine the evaluation index of all kinds of ammunition, (2) evaluate all kinds of ammunition according to the evaluation index, and (3) select the appropriate evaluation model to optimize the ammunition order.

\section{Determination and Calculation of Evaluation Index for Ammunition Type Optimization}

Ammunition damage ability is a quantitative description of the damage effect. Ammunition damage effect [38] refers to the physical and chemical damages to the target caused by the damage element generated at the end of its trajectory, including the fragment damage effect, blasting effect, combustion effect, armor piercing effect, armor breaking effect, armor scabbing effect, and soft killing effect [39]. The antidamage ability of the target is mainly expressed by the limit value of target vulnerability [40]. The matching degree of the single damage effect is measured by the matching degree of ammunition target damage ability [2], and the expression formula is as follows:

$$
r_{i j l}(P)=\frac{W_{i l}}{V_{j l}(P)},
$$

where $W_{i l}$ is the maximum damage ability value of $i$ ammunition under the damage effect $l$, and $V_{j l}(P)$ is the limit value of antidamage ability of $j$ target when it reaches damage degree $P$ under the damage effect $l$.

In order to evaluate all kinds of ammunition quantitatively, seven evaluation indexes, such as fragment killing ability matching degree, blasting ability matching degree, combustion ability matching degree, armor piercing ability matching degree, armor breaking ability matching degree, armor crushing ability matching degree, and soft killing, are selected to construct the evaluation index system of ammunition type optimization, as shown in Figure 1. The matching degree of seven kinds of damage ability can be obtained by the relevant damage ability formula in [38-40]. The damage ability index of ammunition is given in Table 1.

\section{Ammunition Type Optimization Model}

4.1. Index Value Processing. Generally, the index types are divided into benefit type, cost type, fixed type, deviation type, and interval type. Among them, the benefit index means that the larger the index value, the better; the cost index is that the smaller the index value, the better; the fixed index is that the closer the index value is to a fixed value $\alpha$, the better; the deviation index is that the more the index value deviates from a fixed value $\beta$, the better; and interval index means that the closer the index value is to a fixed interval in $\left[q_{1}, q_{2}\right]$, the better. In order to facilitate unified calculation and processing, the original index value matrix should be forward processed, so that the index value type can be transformed into very large data. According to formula (2), for the matching degree of single damage ability, the closer $W_{i l}$ and $V_{j l}(P)$ are, that is, the matching degree value approaches 1, the better the matching effect is. Therefore, the seven indexes in the evaluation index system of ammunition type optimization are all fixed indexes, and the forward scheme is as follows. Equations should be provided in a text format, rather than as an image. Microsoft Word's equation tool is acceptable.

$$
\widehat{y}_{i l}=1-\frac{y_{i l}-\alpha_{l}}{\max _{i}\left|y_{i l}-\alpha_{l}\right|},
$$

where $\alpha_{l}=1$. The matrix after normalization is obtained.

$$
D^{\prime}=\left[\begin{array}{cccc}
\hat{y}_{11} & \hat{y}_{12} & \cdots & \hat{y}_{1 k} \\
\hat{y}_{21} & \widehat{y}_{22} & \cdots & \widehat{y}_{2 k} \\
\vdots & \vdots & \vdots & \\
\hat{y}_{n 1} & \hat{y}_{n 2} & \cdots & \widehat{y}_{n k}
\end{array}\right] .
$$

In order to avoid the incommensurability caused by different dimensions and dimensional units of indicators, it is necessary to standardize the matrix after normalization. The standardized matrix is expressed as

$$
Z=\left[\begin{array}{cccc}
z 11 & z 12 & \cdots & z 1 k \\
z 21 & z 22 & \cdots & z 2 k \\
\vdots & \vdots & \vdots & \\
z n 1 & z n 2 & \cdots & z n k
\end{array}\right] .
$$

The element in $Z$ is

$$
z_{i l}=\frac{\widehat{y}_{i l}}{\sqrt{\sum_{i=1}^{n} \hat{y}_{i l}^{2}}} .
$$

After the normalization and forward processing, the data in the matrix of the evaluation index of ammunition type optimization have been transformed into very large data.

4.2. Determining the Weight of Evaluation Index by the Entropy Weight Method. Nowadays, the battlefield environment is complex and changeable, so it is very limited to determine the weight only by subjective judgment. Therefore, this study selects the entropy weight method [41] of the objective weight method to weight the evaluation index. The entropy weight method is based on the change degree of index to determine the weight, reduce the subjective randomness of weight determination, and make the weight determination objective and reasonable.

Calculate the probability matrix $P$, and the calculation formula of element $p_{i l}$ in $P$ is as follows:

$$
p_{i l}=\frac{z_{i l}}{\sum_{i=1}^{n} z_{i l}} \text {. }
$$

Calculate the information entropy of each evaluation index:

$$
e_{l}=-\frac{1}{\ln n} \sum_{i=1}^{n} p_{i l} \ln \left(p_{i l}\right) \text {, }
$$

where the larger $e_{l}$ is, the greater the information entropy of the $l$ evaluation index is, that is, the less information of the $l$ evaluation index is, so the information utility value is 


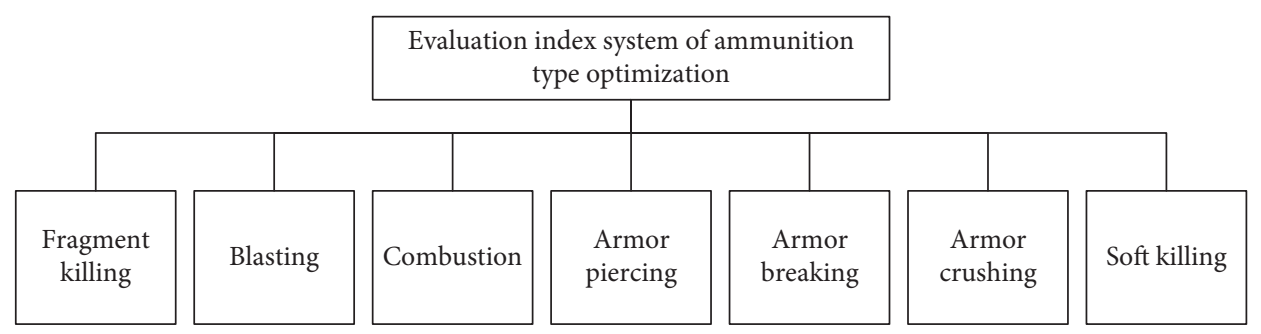

Figure 1: Evaluation index system of ammunition.

Table 1: Ammunition damage capabilities index.

\begin{tabular}{|c|c|}
\hline$l$ & Ammunition damage capabilities index \\
\hline $\begin{array}{l}\text { Fragment } \\
\text { killing }\end{array}$ & Kill area, number of effective kill fragments, average fragment velocity, mass, and fragment distribution density \\
\hline Blasting & ssure at a certain distance, explosive \\
\hline Com & \\
\hline Arm & $\begin{array}{r}\text { Thickness of armor plate penetrating a certain angle at } \\
\text { at a }\end{array}$ \\
\hline Arm & $\begin{array}{l}\text { d number of residual jet penetrating aftereffect target } \\
\text { s and interval }\end{array}$ \\
\hline $\begin{array}{l}\text { Armo } \\
\text { Soft k }\end{array}$ & $\begin{array}{l}\text { The mass and velocity of lamina, the thickness of target, and the overpressure of shock wave at a certain distance } \\
\text { Microwave energy density, explosion field overpressure }\end{array}$ \\
\hline
\end{tabular}

$$
d_{l}=1-e_{l}
$$

The weight of each evaluation index is obtained by normalizing the information utility value:

$$
\omega_{l}=\frac{d_{l}}{\sum_{l=1}^{k} d_{l}} .
$$

4.3. Ammunition Type Optimization Based on VIKOR. The VIKOR method is a compromise ranking method based on ideal point solution proposed by Opricovic. Compromise $[42,43]$ is an agreement reached by mutual compromise of indexes, which is developed from Lp-metric:

$$
\left\{L_{(p, i)}=\left\{\sum_{l=1}^{k}\left[\frac{\omega_{l}\left(f_{l}^{+}-f_{i l}\right)}{f_{l}^{+}-f_{l}^{-}}\right]^{p}\right\}^{1 / p}\right\},
$$

where $1 \leq p \leq \infty, L_{(p, i)}$ is the distance from ammunition $a_{i}$ to the ideal solution, $f_{l}^{+}$is the positive ideal solution, and $f_{l}^{-}$is the negative ideal solution. The compromise [3] of the VIKOR method is embodied in maximizing group benefit $S_{i}=L_{(1, i)}$ and minimizing individual regret $R_{i}=L_{(\infty, i)}$, which eventually leads to compromise solutions. The calculation steps [44] are as follows.

Step 1: determine the positive and negative ideal solutions of each index, and we can gain

$$
\begin{aligned}
& f_{l}^{+}=\max _{i} f_{i l}, \\
& f_{l}^{-}=\min _{i} f_{i l} .
\end{aligned}
$$

Where $f_{i l}$ is the $l$ evaluation value of the $i$ ammunition.
Step 2: calculate the group benefit value $S_{i}$ and individual regret value $R_{i}$ of all kinds of ammunition, and we can gain

$$
\begin{aligned}
S_{i} & =\sum_{l=1}^{k} \omega_{l} \frac{\left(f_{l}^{+}-f_{i l}\right)}{\left(f_{l}^{+}-f_{i}^{-}\right)}, \\
R_{i} & =\max _{l}\left[\omega_{l} \frac{\left(f_{l}^{+}-f_{i l}\right)}{f_{l}^{+}-f_{i}^{-}}\right],
\end{aligned}
$$

Where $\omega_{l}$ is calculated by the entropy weight method in the previous section.

Step 3: calculate the compromise evaluation value of all kinds of ammunition, and we can gain

$$
Q_{i}=v\left(\frac{S_{i}-S^{+}}{S^{-}-S^{+}}\right)+(1-v)\left(\frac{R_{i}-R^{+}}{R^{-}-R^{+}}\right),
$$

Where $S^{-}=\max _{i} S_{i}, S^{+}=\min _{i} S_{i}, R^{-}=\max _{i} R_{i}$, and $R^{+}=\min _{i} R_{i} . v \in[0,1]$ is the decision-making mechanism coefficient. When $v>0.5$, choose the type of ammunition according to the decision-making mechanism of maximizing group benefit; when $v<0.5$, choose the type of ammunition according to the decision-making mechanism of minimizing individual regret; and when $v=0.5$, the type of ammunition is selected according to the eclectic decision-making mechanism, that is, the group utility is maximized and the individual regret is minimized in a balanced way. In this case, the comprehensive evaluation of ammunition is taken into account, and the negative impact of individual poor indicators is prevented from being neutralized by other indicators. Therefore, in this study, $v=0.5$. 
Step 4: according to the group benefit value $S_{i}$, individual regret value $R_{i}$, and compromise evaluation value $Q_{i}$, ammunition types are arranged in the ascending order, and the increasing sequence $a^{(1)}, a^{(2)}, \ldots, a^{(n)}$ of $Q_{i}$ value is obtained. Then, the optimization is carried out according to the following two sorting rules:

Rule 1: $Q\left(a^{(2)}\right)-Q\left(a^{(1)}\right) \geq(1 / n-1)$

Rule 2: $a^{(1)}$ is the first in the $S_{i}$ value increasing sequence and $R_{i}$ value increasing sequence

If $a^{(1)}$ satisfies the above two rules at the same time, then $a^{(1)}$ is the optimal ammunition type. If the above two rules cannot be established at the same time, a compromise scheme is obtained.

(1) If rule 2 is not met, $a^{(1)}$ and $a^{(2)}$ are the best ammunition types

(2) If rule 1 is not met, then a set $A=\left\{a^{(1)}, a^{(2)}, \ldots, a^{(U)}\right\}$ of compromised ammunition categories will be gained. Whereas, the maximum value of $U$ is determined by $Q\left(a^{(U)}\right)-Q\left(a^{(1)}\right)<(1 / n-1)$.

\section{Case Analysis}

The conclusions section should clearly explain the main findings and implications of the work, highlighting its importance and relevance.

In order to verify the scientificity of the VIKOR-based ammunition type optimization model, the following cases are used to test the model. Assuming that the set of targets sorted by importance is $T=\left\{t_{j} \mid j=1,2, \ldots, m\right\}$, there are five kinds of ammunition available at present, that is, ammunition evaluation index set is $A=\left\{a_{1}, a_{2}, a_{3}, a_{4}, a_{5}\right\}$, and ammunition evaluation index set is $C=\left\{c_{1}, c_{2}, c_{3}\right.$, $\left.c_{4}, c_{5}, c_{6}, c_{7}\right\}$. For target, the evaluation index value of each ammunition is obtained according to the calculation formula in literature [38-40], as given in Table 2 .

5.1. Data Processing. According to equations (3)-(6), the ammunition evaluation index matrix $D^{\prime}$ after normalization and the ammunition evaluation index matrix $Z$ after normalization can be calculated:

$$
\begin{aligned}
D^{\prime} & =\left[\begin{array}{cccccccc}
0.5 & 0.831356 & 0.04026 & 0.079673 & 0.005556 & 0 & 0.014407 \\
0.25 & 0.741525 & 0.037662 & 0 & 0.007071 & 0.002299 & 0.014407 \\
0.25 & 0.317797 & 0.038961 & 0.029622 & 0 & 0.057471 & 0.059322 \\
0 & 0.042373 & 0.012987 & 0.79571 & 0.015152 & 0.448276 & 0 \\
0.5 & 0 & 0 & 0.948927 & 0.020202 & 0.678161 & 0.008475
\end{array}\right], \\
Z & =\left[\begin{array}{cccccccc}
0.632456 & 0.717165 & 0.585636 & 0.064185 & 0.207252 & 0 & 0.22762 \\
0.316228 & 0.639673 & 0.547853 & 0 & 0.263776 & 0.002821 & 0.22762 \\
0.316228 & 0.274146 & 0.566744 & 0.023864 & 0 & 0.07052 & 0.937257 \\
0 & 0.036553 & 0.188915 & 0.641026 & 0.565233 & 0.550058 & 0 \\
0.632456 & 0 & 0 & 0.764458 & 0.753645 & 0.832139 & 0.133894
\end{array}\right] .
\end{aligned}
$$

5.2. Ammunition Type Optimization. The weight of evaluation index calculated by the entropy weight method (7)-(10) combined with matrix is $\omega=(0.0815,0.1462,0.0863$, $0.2059,0.1024,0.2218,0.1559)$.

Combining formulas (13)-(15), let $v=0.5$; calculate group benefit value $S_{i}$, individual regret value $R_{i}$, and compromise evaluation value $R_{i}$ of various ammunition, as given in Table 3.

According to the value of $Q_{i}$, the priority of all kinds of ammunition is $a_{5}, a_{4}, a_{3}, a_{1}$, and $a_{2}$, among which, the minimum $Q_{i}$ value of the fifth ammunition application scheme is $\left(Q_{i}=0\right)$. It can be seen from Table 3 that $Q\left(a^{(2)}\right)-Q\left(a^{(1)}\right)=0.394147-0 \geq(1 / 5-1)=0.25$, and $a_{5}$ ranks first in $S_{i}$ and $R_{i}$, so the ammunition application scheme $a_{5}$ meets both rule 1 and rule 2 , that is, $a_{5}$ is the best choice in the ammunition application scheme.
5.3. Sensitivity Analysis. In the VIKOR method, the change of decision mechanism coefficient $v$ has an important effect on the result of ammunition type optimization. Through sensitivity analysis, the stability of the VIKOR method in ammunition type optimization can be verified. In the interval $[0,1]$, the decision-making mechanism coefficient $v$ is assigned with an interval of 0.1 . When different decision-making mechanism coefficients $v$ are selected, the VIKOR method is used to obtain the ammunition type optimization sequence. A total of 11 tests were carried out, and the sensitivity analysis results as shown in Figure 2 is obtained.

It can be seen from Figure 2 that the $Q_{i}$ values of $a_{5}$ and $a_{4}$ always rank in the top two in the process of the change of the decision-making mechanism coefficient $v$, indicating that $a_{5}$ and $a_{4}$ are not sensitive to the change of the decision- 
TABLE 2: Evaluation index value system of ammunition.

\begin{tabular}{cccccccc}
\hline & \multicolumn{6}{c}{ Evaluation index value of ammunition type optimization } \\
$a_{i}$ & 1 & 2 & 3 & 4 & 5 & 6 & 7 \\
\hline 1 & 1.4 & 1.144203 & 0.064557 & 0.099 & 0.0155 & 0.054348 & 0.030833 \\
2 & 1.6 & 0.778986 & 0.062025 & 0.021 & 0.017 & 0.056522 & 0.030833 \\
3 & 0.4 & 0.416667 & 0.063291 & 0.05 & 0.01 & 0.108696 & 0.075 \\
4 & 0.2 & 0.181159 & 0.037975 & 0.8 & 0.025 & 1.521739 & 0.016667 \\
5 & 0.6 & 0.144928 & 0.025316 & 0.95 & 0.03 & 1.304348 & 0.025 \\
\hline
\end{tabular}

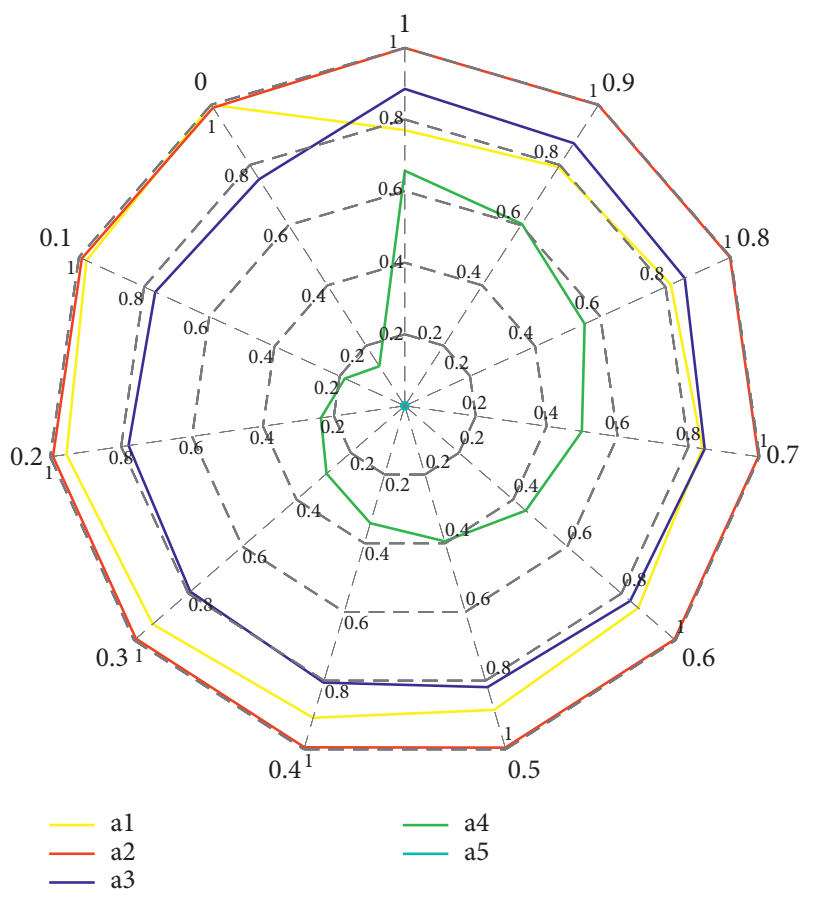

FIgURE 2: Sensitivity analysis.

TABle 3: Value $S, R$, and $Q$ of ammunition.

\begin{tabular}{cccccc}
\hline \multicolumn{5}{c}{ Types of ammunition } \\
& $a_{1}$ & $a_{2}$ & $a_{3}$ & $a_{4}$ & $a_{5}$ \\
\hline$S_{i}$ & 0.602768 & 0.673486 & 0.638220 & 0.567832 & 0.365714 \\
$R_{i}$ & 0.222000 & 0.221247 & 0.203186 & 0.156000 & 0.146000 \\
$Q_{i}$ & 0.885113 & 0.995049 & 0.818934 & 0.394147 & 0.000000 \\
\hline
\end{tabular}

making mechanism coefficient $v$. When $v \in[0.7,1]$, the decision is made according to the mechanism of maximizing group utility, and the comprehensive evaluation of ammunition is mainly considered, which reduces the weight of the individual regret value. At this time, $a_{1}$ exceeds $a_{3}$ to the third place, indicating that there are individual poor evaluation indicators in $a_{1}$. When the group utility weight increases, individual poor evaluation indicators are neutralized by other indicators, resulting in a change in the ranking of $a_{1}$. Although the order of $a_{1}$ and $a_{3}$ changed during the experiment, the order of optimal ammunition and suboptimal ammunition never changed, and the sequence of ammunition only changed three times in 11 sensitivity experiments, indicating the stability of the evaluation results of the VIKOR method.
TABLE 4: Contrast result.

\begin{tabular}{ccccc}
\hline & \multicolumn{2}{c}{ TOPSIS method } & \multicolumn{2}{c}{ VIKOR method } \\
$a_{i}$ & $C_{i}$ & Sequencing & $Q_{i}$ & Sequencing \\
\hline$a_{1}$ & 0.337 & 4 & 0.885113 & 4 \\
$a_{2}$ & 0.300 & 5 & 0.995049 & 5 \\
$a_{3}$ & 0.393 & 3 & 0.818934 & 3 \\
$a_{4}$ & 0.487 & 2 & 0.394147 & 2 \\
$a_{5}$ & 0.604 & 1 & 0.000000 & 1 \\
\hline
\end{tabular}

5.4. Comparative Analysis. In order to compare the effectiveness of the VIKOR method, the TOPSIS method is used to deal with the evaluation index values in the case analysis, and the ranking results of schemes are compared with the decision results obtained by the VIKOR method. TOPSIS is a decision-making method based on the relative distance between each index of the current evaluation scheme and the positive and negative ideal solutions. The calculation formula is $C_{i}=\left(D_{i}^{-} / D_{i}^{-}+D_{i}^{+}\right)$, where the larger the $C_{i}$ value is, the closer the ideal scheme will be. The comparison results of ammunition types obtained by the TOPSIS method and VIKOR method are given in Table 4.

The comparison results show that the TOPSIS method and VIKOR method get the same sort of ammunition, and the best ammunition is $a_{5}$, which verifies the effectiveness of the VIKOR method for ammunition type optimization decision. Although the decision results of the two methods are the same, the difference of $C_{i}$ value of the five schemes in the TOPSIS method is small, and the difference between optimal ammunition $a_{5}$ and $a_{1}, a_{2}, a_{3}$, and $a_{4}$ is $0.267,0.304$, 0.211 , and 0.117 , respectively. The difference of $Q_{i}$ value in the VIKOR method is larger, which is $0.885113,0.995049$, 0.818934 , and 0.394147 , respectively. It shows that the decision information of the VIKOR method is more reliable and can distinguish the ammunition types more significantly. In addition, the VIKOR method takes into account the compromise relationship between group benefits and individual regrets, and the coefficient of the decision-making mechanism can be adjusted according to the nature of ammunition. If individual regret is not taken into account, the group utility of the VIKOR evaluation method is similar to that of the linear weighted summation method, that is, it is ranked by the comprehensive evaluation of seven indicators of ammunition, and if individual regret is taken into account, the VIKOR evaluation method can prevent the negative effects of individual poor indicators from being neutralized by other indicators, so the VIKOR method has flexibility in the optimization of ammunition types.

\section{Conclusion}

In this study, when studying the method of ammunition type optimization, according to the characteristics of ammunition damage ability and target vulnerability, the matching degree function of ammunition target damage capability is constructed, based on which the evaluation index system of ammunition type optimization is designed, and an eclectic ammunition type optimization model is constructed by combining the entropy weight method with the VIKOR 
method. The proposed method avoids the arbitrariness of subjective empowerment and ensures the minimum individual regret while pursuing the maximization of group utility. The stability and effectiveness of the model are verified by sensitivity analysis and comparative analysis. The research results show that the ammunition type optimization model based on damage capability matching proposed in this study is stable, effective, and feasible and can provide a scientific basis for ammunition support decision-making.

\section{Data Availability}

The data used to support the findings of this study are included within the article.

\section{Conflicts of Interest}

The authors declare that they have no conflicts of interest.

\section{Acknowledgments}

This work was supported by the Grant Program of Military Graduate Students of China (JY2020B086) and the Key Military Scientific Research Projects of China (LJ20202C050369).

\section{References}

[1] J. Chi, X. D. Li, Z. T. An et al., Ordnance Supply Engineering, PLA Press, Beijing, China, 2000.

[2] L. X. Wang, Research on Mission Oriented Demand Prediction of Suppressive Weapons and Ammunition, College of Ordnance Engineering, Shijiazhuang, China, 2013.

[3] S. L. Yang, Research on Intelligent Reasoning and Optimization Method of Equipment Command Decision in Uncertain Environment, National University of Defense Technology, Changsha, China, 2016.

[4] S. P. Lloyd and H. S. Witsenhausen, "Weapons allocation is np-complete," in Proceedings of the IEEE Summer Conference on Simulation, Claymont, DE, USA, November 1986.

[5] A. Kline, D. Ahner, and R. Hill, "The weapon-target assignment problem," Computers \& Operations Research, vol. 105, pp. 226-236, 2019.

[6] P. Hossein and M. Athans, "An asymptotic result for the multi-stage weapon-target allocation problem," in Proceedings of the IEEE Conference on Decision \& Control, Honolulu, HI, USA, December 1990.

[7] M. Samuel, "A review of the literature on the missile-allocation problem," Operations Research, vol. 18, no. 2, pp. 334-373, 1970.

[8] O. Kwon, K. Lee, D. Kang, and S. Park, "A branch-and-price algorithm for a targeting problem," Naval Research Logistics, vol. 54, no. 7, pp. 732-741, 2007.

[9] S. J. Shao, Research on Weapon Target Assignment Based on Intelligent Algorithm, Harbin Engineering University, Harbin, China, 2019.

[10] Z. R. Bogdanowicz, "Advanced input generating algorithm for effect-based weapon-target pairing optimization," IEEE Transactions on Systems, Man, and Cybernetics - Part A: Systems and Humans, vol. 42, no. 1, pp. 276-280, 2012.

[11] R. H. Wang and C. Wang, "Variable value control technology of genetic algorithm for weapon target assignment problem of ground strike," Journal of China Ordnance, vol. 37, no. 10, pp. 1889-1895, 2016.

[12] M. Chen, Research and Application of Particle Swarm Optimization in Shipborne Weapon Target Assignment, Wuhan University of Science and Technology, Wuhan, China, 2018.

[13] C. A. Cullenbine, "Tabu search approach to the weapons assignment model," 2000.

[14] C. B. Liu, Z. M. Qiu, L. Wu et al., "Research status and prospect of dynamic weapon target assignment," Electro Optics and Control, vol. 17, no. 11, pp. 43-48, 2010.

[15] P. Hosein and J. Walton, "Dynamic weapon target assignment problems with vulnerable c2 nodes," 1786.

[16] P. Hosein and M. Athans, "Preferential defense strategies, part1 : the static case," 1990.

[17] T. Sikanen, "Solving weapon target assignment problem with dynamic programming," 2008.

[18] C. Besse and B. Chaibdraa, An Efficient Model for Dynamic and Constrained Resource Allocation Problems, DRAA, London, UK, 2013.

[19] M. F. HOCAOğLU, "Weapon target assignment optimization for land based multi-air defense systems: a goal programming approach," Computers \& Industrial Engineering, vol. 128, no. 2, pp. 681-689, 2019.

[20] K.-P. Lin and K.-C. Hung, "An efficient fuzzy weighted average algorithm for the military UAV selecting under group decision-making," Knowledge-Based Systems, vol. 24, no. 6, pp. 877-889, 2011.

[21] B. Jiang, X. A. Liang, and J. Tang, "Multi attribute decision making of equipment support scheme based on effectiveness evaluation," Fire Control \& Command Control, vol. 45, no. 11, pp. 88-93, 2020.

[22] Q. Y. F Peng and J. Jun, "Evaluation method of equipment support effect based on multi-layer fuzzy comprehensive evaluation," Modern Defense Technology, vol. 43, no. 6, pp. 163-168, 2015.

[23] J. Lee, S.-H. Kang, J. Rosenberger, and S. B. Kim, “A hybrid approach of goal programming for weapon systems selection," Computers \& Industrial Engineering, vol. 58, no. 3, pp. 521-527, 2010.

[24] X. G. Wang, X. F. He, and X. Q. Wu, "Evaluation and optimization of air surface guided ammunition configuration scheme based on multi-attribute compromise decision," Journal of Projectiles, Rockets, Missiles and Guidance, vol. 39, no. 1, pp. 139-142, 2019.

[25] D. Wu and J. M. Mendel, "Computing with words for hierarchical decision making applied to evaluating a weapon system," IEEE Transactions on Fuzzy Systems, vol. 18, no. 3, pp. 441-460, 2010.

[26] M. Dağdeviren, S. Yavuz, and N. Kılınç, "Weapon selection using the AHP and TOPSIS methods under fuzzy environment," Expert Systems with Applications, vol. 36, no. 4, pp. 8143-8151, 2009.

[27] Z. S. Xu, Research on Several Kinds of Multi-Attribute Decision-Making Methods, Southeast University, Nanjing, China, 2003.

[28] N. Jiang, Research on Multi-Attribute Decision-Making Theory Model and Method in Electronic Countermeasure Simulation System, Dalian University of Technology, Liaoning, China, 2000.

[29] L. Chen and Y. Z. Wang, "Research on integrated evaluation decision method based on entropy weight coefficient and TOPSIS," Control and Decision, vol. 18, no. 4, pp. 456-459, 2003. 
[30] Y. S. Gong and H. Yang, "Artillery battlefield target value priority based on information entropy and topsis method," Ship Electronic Engineering, vol. 31, no. 11, pp. 33-36, 2011.

[31] W. Z. Huang, L. Y. Ai, and B. Peng, "Methodology to artillery position option based on entropy weighting and topsis," Ship Electronic Engineering, vol. 30, no. 8, pp. 39-41, 2010.

[32] D. J. Xu, Y. B. Wang, and J. Xue, "Preference for tank element operation plan based on entropy weight,," Ordnance Industry Automation, vol. 28, no. 4, pp. 48-50, 2009.

[33] J. W. Yang, H. L. Wu, and X. J. Pan, "Based on entropy weight method to the mix-cluster of anti-aircraft ground army topsis combat deployment scheme optimization," Fire Control \& Command Control, vol. 37, no. 12, pp. 184-187, 2012.

[34] C. F. Xu, J. S. Zhao, and F. L. Zhang, "Optimality study of distribution scheme of field maintenance equipment for vehicles in wartime,", Journal of Academy of Equipment, vol. 24, no. 2, pp. 131-133, 2013.

[35] S. L. Yang, P. Wang, G. Li et al., "Group decision making model for weapon selection using extended vikor method under intuitionistic fuzzy environment,", Journal of System Simulation, vol. 27, no. 9, pp. 2165-2175, 2015.

[36] Y. C. Wang, X. D. Miao, and Y. T. Wang, "Operational readiness evaluation model of new type shipborne operational control system," Journal of the Academy of Equipment Command \& Technology, vol. 19, no. 3, pp. 17-22, 2008.

[37] X. M. Chen and Y. Z. Liu, "Multi granularity hesitant fuzzy language VIKOR group recommendation method based on Entropy Weight," Control and Decision, vol. 33, no. 1, pp. 111-118, 2018.

[38] Z. X. Huang and X. D. Zu, Endpoint Effect, Science Press, Beijing, China, 2014.

[39] J. P. Yin, Z. J. Wang, and Y. Tan, Ammunition Science, Beijing Institute of Technology Press, Beijing, China, 2014.

[40] G. W. Zhang, Terminal Effect and Range Test, Beijing Institute of Technology Press, Beijing, China, 2009.

[41] F. Hu, Z. H. Liu, and S. C. Li, "Research on risk assessment of public engineering projects based on entropy weight method and VIKOR method," Journal of Hunan University (Natural Science Edition), vol. 39, no. 4, pp. 83-86, 2012.

[42] X. K. Bi, X. Wang, and W. Gao, "Research on evaluation of independent innovation capability of technology-based small and medium-sized enterprises based on VIKOR method," Science \& Technoloy Progress and Policy, vol. 28, no. 1, pp. 113-119, 2011.

[43] W. Q. Jiang, "Risk based fuzzy multi criteria decision making method based on prospect theory and VIKOR," Control and Decision, vol. 29, no. 12, pp. 2287-2291, 2014.

[44] Y. Yuan, T. Guan, X. B. Yan et al., "Supplier selection decision model based on hybrid VIKOR method," Control and Decision, vol. 29, no. 3, pp. 551-560, 2014. 